\title{
Palabras de Instalación Foro "Los códigos en la construcción en Colombia: Aproximaciones y Aplicaciones”
}

\author{
Opening Words Forum "Building Codes in Colombia: Approximations and Implementation”
}

\author{
Alonso Cárdenas ${ }^{(1)}$ \\ (1)Director de Espacio Urbano y Territorial, Ministerio de Vivienda, Bogotá, Colombia. acardenas@minvivienda.gov.co
}

DOI: http://dx.doi.org/10.16924/riua.v0i41.783

El Ministerio de Vivienda, Ciudad y Territorio hizo parte de la estrategia de superación de la pobreza del Gobierno Nacional con la implementación de una nueva política de vivienda cuyo objetivo principal es generar alternativas de acceso a la vivienda para los hogares más pobres y vulnerables del país. En el marco de esta gestión, que no solo se ha concentrado en el alcance de la meta de un millón de viviendas, sino también en la tarea de fortalecer los mecanismos normativos y regulatorios del país en materia de vivienda y desarrollo urbano, se ha avanzado en el desarrollo del siguiente marco normativo:

1. Uno de los principales temas de interés para este Ministerio se relaciona con las normas de sismo resistencia, por tanto, en el marco del acompañamiento constante a la Comisión Asesora Permanente para el Régimen de Construcciones Sismo Resistentes del país, se han obtenido importantes logros como la actualización del reglamento de sismo resistencia (Ley 400 de 1997 - NSR-10), lo cual permite la verificación por parte de las entidades competentes de los criterios y los requisitos mínimos para el diseño, la construcción y la supervisión técnica de las edificaciones y evaluar los impactos que esta pueda tener en el territorio.

Con respecto a lo anterior, es importante tener en cuenta que actualmente en Colombia, pese a la descentralización del desarrollo urbano generado por la disposición establecida por la Ley 388 de 1997 de permitir a los gobiernos

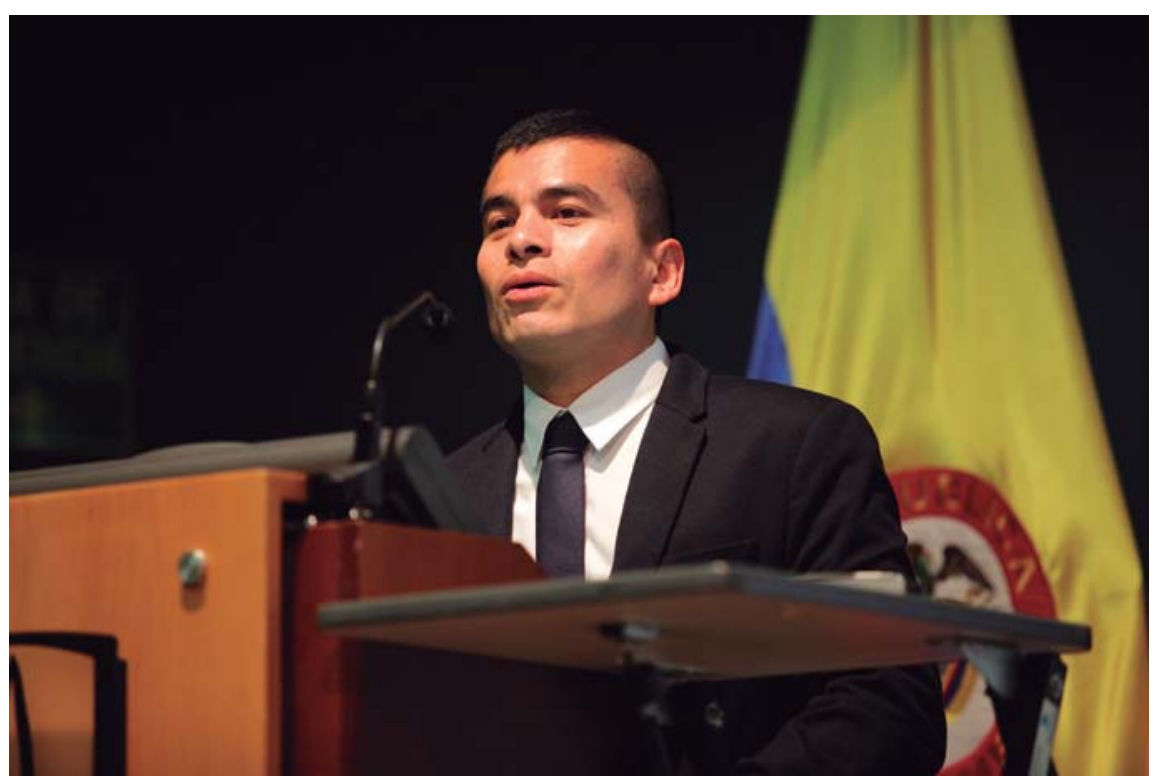

Alonso Cárdenas. Fuente: Archivo Particular, Universidad de los Andes

locales la formulación de los planes de ordenamiento territorial, los códigos de la construcción siguen estando centralizados, lo que garantiza la uniformidad de las normas relacionadas en el territorio nacional.

2. Una de las metas más importantes del Gobierno Nacional es la expedición del primer decreto de construcción sostenible, por medio del cual se adopta la Guía para el ahorro de agua y de energía en edificaciones. Esta iniciativa responde a la necesidad de fortalecimiento del desarrollo urbano, incorporando parámetros de sostenibilidad ambiental en el diseño y construcción de edificaciones, mediante la definición de estándares para el uso eficiente de los recursos de agua y de energía, lo cual permitirá mejorar la calidad y el confort de las edificaciones e impulsar la industria de la construcción para hacerla más competitiva y sostenible.

Esto significa que se crearán desarrollos urbanísticos sostenibles y articulados con los modelos de ocupación territorial, para lo cual, también es necesario seguir trabajando en el fortalecimiento de las disposiciones establecidas en la Ley 388 de 1997 sobre los Planes de Ordenamiento Territorial.

3. Con el fin de fortalecer el marco normativo de seguridad en las edificaciones, se está trabajando en un proyecto de ley cuya finalidad principal es controlar la actividad constructora y la de quienes ejercen funciones públicas para el licenciamiento urbanístico. Dicho proyecto se fundamenta en las siguientes medidas: (i) Exigencia de 
pólizas obligatorias para proyectos de vivienda nueva que protejan a los compradores de vivienda cuando se vean afectados por un desastre o fallas constructivas o estructurales de la edificación. (ii) Creación del Fondo Nacional para la Estabilidad y Reconstrucción de la Vivienda Nueva con el objetivo de garantizar a los adquirentes de vivienda nueva, el reemplazo integral o la reconstrucción de los inmuebles en aquellos casos en los que estos colapsen, perezcan o amenacen ruina como consecuencia de las deficiencias del proceso constructivo, del suelo, de los materiales o de los diseños utilizados en la construcción de las edificaciones. (iii) Eliminación de todas las excepciones que permitan a los municipios o curadores autorizar a los constructores para que ellos mismos controlen la ejecución en las obras y, en cambio, se establece que los proyectos deberán someterse a una supervisión técnica independiente del constructor. (iv) Creación del Registro Único Nacional de Profesionales acreditados para adelantar las labores de diseño, revisión y supervisión de que trata la Ley 400 de 1997, el cual será administrado por el
Consejo Profesional Nacional de Ingeniería y Profesiones Afines. (v) Regulación de la obligación relacionada con la obtención del certificado de ocupación. (vi) Vigilancia y control de la actividad de los curadores urbanos.

Como se puede ver, el Ministerio de Vivienda, Ciudad y Territorio está en un continuo seguimiento al establecimiento de códigos de construcción como herramientas que permitan regular, revisar y unificar las normas relacionadas con la construcción desde sus diferentes componentes. 